\title{
SURVIVAL - SELECTED DETERMINANTS OF PARTICIPATION
}

\author{
PRZEMYSŁAW PŁOSKONKA
Józef Piłsudski University of Physical Education in Warsaw, Faculty of Tourism and Recreation, Department of Active Forms of Tourism and Recreation

\author{
Mailing address: Przemysław Płoskonka, Faculty of Tourism and Recreation, Department of Active Forms \\ of Tourism and Recreation, 34 Marymoncka Street, 00-968 Warsaw, \\ tel.: + 4822 8343713, e-mail: przemysławploskonka@gazeta.pl
}

\begin{abstract}
Introduction. A growing interest in survival as a tourist and recreational activity raises the need for empirical research into this issue. Unfortunately, a vast majority of authors focus on the technical aspects of survival, ignoring the determinants of this activity. The few existing studies are mostly based on observation and involve small samples. This paper will help complement the body of knowledge concerning this issue. Material and methods. Following a pilot study, the study proper was conducted between 2011 and 2013 using a questionnaire prepared by the author. The analysis was based on the opinions of 594 respondents. The research was conducted during randomly selected survival events, among randomly selected members of survival societies and organisations, and among users of websites dedicated to survival. Results. The respondents usually organised survival activities individually or in a group of friends, forests being the preferred location. The respondents undertook survival activity either sporadically (once every 4-6 months) or sometimes (once every 2-3 months), with individual periods of activity usually lasting 2-3 days. The most popular form of this activity was one-day-long or several-day-long trips with overnight stays, and the activities the respondents performed the most frequently were constructing makeshift shelters, lighting and building campfires, and topography. Conclusions. Survival activity was strongly determined by the accessibility of the natural environment. The persons engaged in survival showed high independence in carrying out their tasks. The survival activities were undertaken in short periods and sporadically, weekend trips (sometimes with an overnight stay) being the most popular form of activity. Basic issues related to survival were the dominant activities performed by the respondents.
\end{abstract}

Key words: tourist and recreational activity, survival, determinants

\section{Introduction}

In popular understanding, survival denotes skills that allow one to continue living in difficult conditions. Thus, it is often referred to as an 'art' and treated as the collected knowledge on how to act in any oppressive and extremely demanding situation $[1,2,3]$. In simple terms, survival is the ability to adapt to new circumstances [4] or a type of self-rescue [5]. Survival is also understood as a field of human activity dedicated to preserving one's life as an individual or species, as well as preserving one's habitat, i.e. the broadly defined social and natural environment [5].

Survival treated as an art is the ability to adapt to external conditions and to adjust external conditions to one's needs $[4,6]$. K. J. Kwiatkowski [6] states that the word 'art' in 'the art of survival' serves to underline this unique skill of applying praxeological knowledge, because 'art' concerns the most effective way possible of satisfying one's needs using the least possible effort and a creative attitude to searching for solutions.

Today, survival is a complex form of activity carried out in various modes. There is a tendency to use the term 'survival' to refer to any form of activity, including physical activity, that is related to risk, requires improvisation, and carries a large emotional charge. Consequently, the phenomenon should be analysed - at the very least - from a two-fold perspective. Firstly, it can be seen as part of security education and preparing soldiers for military operations. The art of survival for soldiers in volves issues related to maintaining one's life in isolation from friendly forces and other individuals and communities as well as being able to combat forces that aim to capture or kill the soldier [7]. Secondly, it can be considered a form of tourism and recreation related to the development of qualified tourism (in Poland) and adventure recreation (throughout the world). From this viewpoint, survival is defined as a voluntary form of spending free time in the open with the aim of experiencing an adventure, gaining knowledge, and honing skills related to surviving in oppressive conditions, including natural conditions [8]. The primary point of this activity is achieving independence from external (civilisation-related) factors and seeking ways to overcome one's weaknesses.

Physical culture sciences that address, among other issues, physical activity performed during leisure time attempt to investigate the determinants, barriers, and motivations related to it. These investigations are done in order to assist physical culture organisations in creating optimal conditions for free-time activity and ensure full satisfaction on the part of its participants. Unfortunately, the scientific achievements of these organisations, while rich, include few studies on survival. A vast majority of authors $[1,2,5]$ focus on the technical aspects of survival, ignoring the determinants of this activity. The few existing studies [9, $10,11,12]$ are mostly based on observation and involve small samples. Due to a growing interest in survival as a tourist and recreational activity, there is a need to conduct more empirical research. This paper will contribute to expanding the body of knowledge concerning this issue.

The aim of this study was to find the determinants of engagement in survival as a form of tourist and recreational activity and to investigate their effect on undertaking survival activity and 
continuing it.

The following hypothesis can be proposed based on the available literature: engagement in survival and the frequency of this activity are determined by environmental factors, the type of activities undertaken, and the manner in which the activities are organised.

\section{Material and methods}

In 2011, a study on survival in Poland was launched at the Józef Piłsudski University of Physical Education in Warsaw. The study employed the diagnostic survey method. The instrument used was a questionnaire prepared beforehand and reviewed during the pilot study. The questionnaire was divided into two parts. The first part comprised 14 open-ended and closed-ended questions concerning the determinants of engagement in survival. The closed-ended questions were composed of statements and assessed on a five-point Likert scale. The second part comprised six questions concerning sociodemographic data. The study was conducted among the participants of three randomly selected survival events (the Combat in the City Course, organised by the 'Strzelec' Riflemen's Association in 2011, the 7th 'Tropiciel' Adventure Orientation Rally, organised by the Centre for Youth Information and Development from Wrocław, and the 7th 'Commando' 24h Military Task Rally, organised by the 'Zielony Talizman' Centre for the Development of Defence from Poznań) and two randomly selected recreation instructor courses for survival (one organised by the Polish Academy of Sports in 2011 and the other organised by Escape and the ProActive Association in 2012). The respondents also included a group of third-year students of tourism and recreation of the Józef Piłsudski University of Physical Education in Warsaw and the university's Branch in Biała Podlaska specialising in survival and the members of survival clubs and associations (the Polish School of Survival Association in Łódź and the Pol-Survival Club of the Polish Tourist and Sightseeing Society in Rzeszów). Furthermore, following an agreement with the website administrators, the questionnaire was conducted among randomly selected registered users of websites dedicated to survival who declared active engagement in the activity ('recon.pl', 'miniportal.harcerski.pl', and 'tactical.pl'). The study was carried out from 2011 to 2013. The analysis was based on the opinions of 594 respondents, which allowed the author to answer questions concerning the selected determinants of survival.

The statistical analysis of the data was divided into stages. In the first stage, the material obtained was presented in a quantitative form. The second stage involved encoding according to the five-point Likert scale. In the third stage, summary statistics were drawn using descriptive statistics, including central tendency statistics (arithmetic mean). Also drawn was the statistical dispersion (standard deviation) for each element of the questionnaire. The fourth stage involved the analysis of statistical significance between the groups compared against each other. Statistical significance was determined using the chisquared test, Friedman's test, and Mann-Whitney U test. Statistical significance was set at $p<0.05$. The STATISTICA 9.0 PL software package for statistical analysis and MS Office Excel 2010 were used for nearly all calculations.

\section{Results}

First and foremost, it should be noted that the small number of previous studies and a lack of data on the number of persons engaged in survival made it difficult to characterise the population of persons engaged in this type of activity. However, based on available studies, participant observation, and own experience, the author of the current study assumed that the study sample did not differ significantly from the entire population of persons engaged in survival and that it represented a relatively full spectrum of persons engaged in survival with different competences, experience, and preferences.

First, the statements about the preferred location for survival activity were tested (fig. 1), i.e. about the set of natural and nonnatural elements that were beneficial for performing survival activities according to the respondents. Certain elements of the recreation opportunity spectrum (ROS) model were used to construct the preference scale. The model included three categories of factors (environmental, social, and organisational) [13]. Furthermore, the categorisation of aspects that are of value for tourists designed by Rogalewski was used [14].

Most respondents preferred forested areas with lakes and rivers and emphasised the wild and untouched character of the surrounding nature. The respondents found catering and accommodation services, cultural attractions, and historical monuments to be the least important aspects of the places they chose for survival activity.

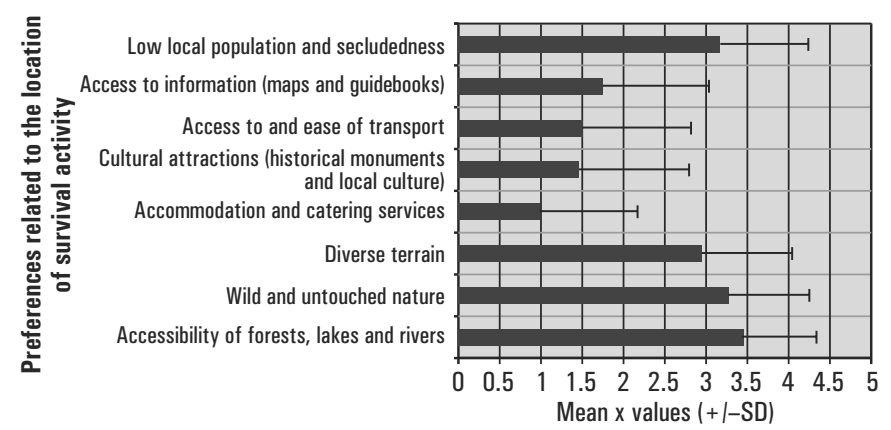

Completely unimportant -0 , Unimportant -1 , Difficult to say -2 , Important -3 , Very Important -4 .

Figure 1. Preferences related to the places chosen for survival activity $(n=594)$

Correlations between a preference for a given location for survival activity and selected sociodemographic variables and between a preference for a given location for survival activity and experience were also tested. No significant correlations were found.

Subsequently, the statements about social preferences related to the organisation of survival activities were tested (fig. 2). The respondents most often organised survival activities on their own or with friends. Few respondents organised them with their families, and nearly $80 \%$ of respondents had never participated in activities offered by an external organiser.

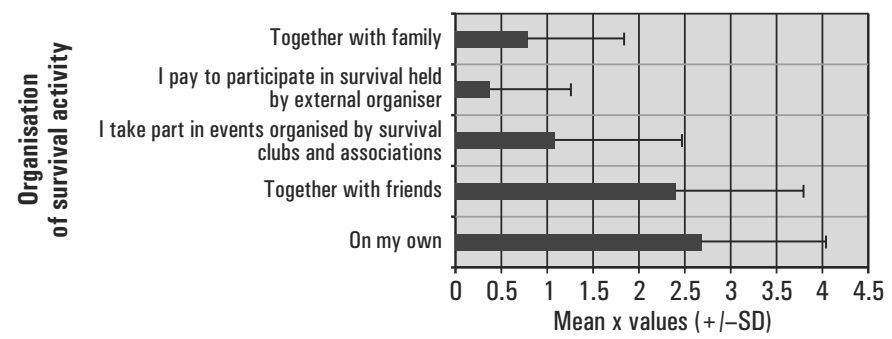

Very rarely (never) -0 , Rarely -1 , Difficult to say -2 , Often -3 , Very often (always) -4 .

Figure 2. Organisation of survival activity $(n=594)$

Correlations between the organisation of survival activities and selected sociodemographic variables and between the or- 
ganisation of survival activities and experience were tested. The sample showed a significant correlation between survival activities organised by survival associations and organisations and experience $(\mathrm{df}=592 ; \mathrm{r}=0.205 ; \mathrm{p}<0.05)$.

Subsequently, the respondents' preferences related to the types of activities engaged in were established. The respondents were divided into 21 groups. Only the most important results are presented in this article due to limitations of space (fig. 3). Most respondents preferred building makeshift shelters, lighting and building campfires, topography, and traversing the terrain. The respondents found city survival, signalling, communication, encryption, and battlefield tactics and simulated military operations to be the least interesting activities.

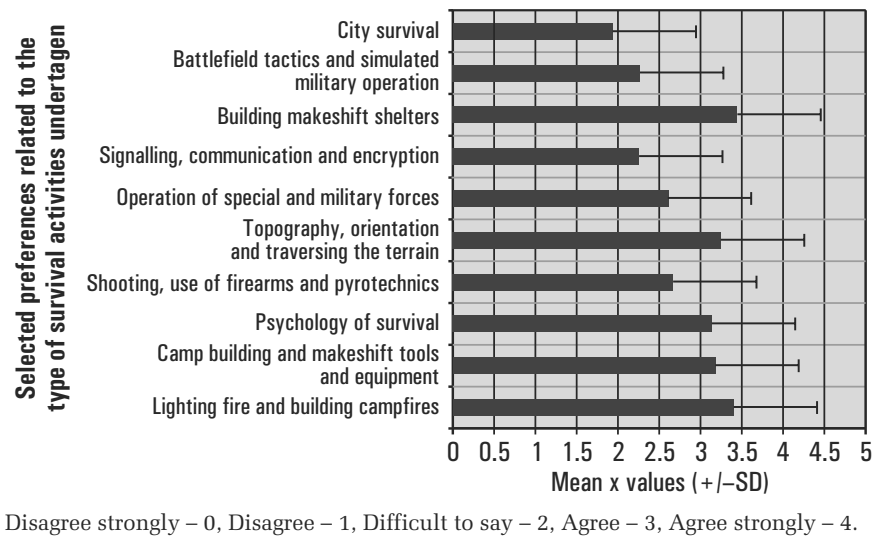

Figure 3. Selected preferences related to the type of survival activities undertaken $(n=594)$

Many correlations were found for the total sample (tab. 1). However, no correlations were found between such variables as income or place of residence and preferences related to the type of survival activities the respondents engaged in.

Table 1. Preferences related to the type of survival activities undertaken according to selected sociodemographic variables and experience

\begin{tabular}{|c|c|c|c|c|}
\hline \multirow{3}{*}{$\begin{array}{l}\text { Preferences related the type } \\
\text { of survival activities }\end{array}$} & & \multicolumn{2}{|c|}{$\begin{array}{l}\text { Sociodemographic } \\
\text { variables }\end{array}$} & \multirow{3}{*}{$\begin{array}{l}\text { Expe- } \\
\text { rience } \\
r\end{array}$} \\
\hline & & \multirow{2}{*}{$\underset{r}{\text { Age }}$} & \multirow{2}{*}{$\begin{array}{c}\text { Education } \\
r\end{array}$} & \\
\hline & $(n=594)$ & & & \\
\hline Self-defence and hand-to-hand combat & Total & $-0,225^{*}$ & NSS & NSS \\
\hline Lighting fire and building campfires & Total & $-0,199 *$ & $-0,230^{*}$ & NSS \\
\hline $\begin{array}{l}\text { Obtaining and cooking meat } \\
\text { and setting traps }\end{array}$ & Total & NSS & $-0,210^{*}$ & NSS \\
\hline $\begin{array}{l}\text { Tracking, covert movement, } \\
\text { and camouflage }\end{array}$ & Total & $-0,196^{*}$ & NSS & NSS \\
\hline Building makeshift shelters & Total & $-0,200^{*}$ & NSS & NSS \\
\hline
\end{tabular}

Significant correlation: * $-\mathrm{p}<0.05$.

Subsequently, preferences related to spending one's free time were analysed by testing the respondents' opinions according to the distribution of individual variables (fig. 4). These preferences indicate what particular forms of spending their free time the respondents chose and what their attitude to other forms of activity was. The most numerous group of respondents declared that survival activity was more important that other forms of tourism and recreation for them and that it was their dominant activity during the holidays. Only one respondent in ten often undertook activities other than survival. Also tested were correlations between preferences related to spending one's free time and selected sociodemographic variables and between preferences related to spending one's free time and experience. No significant correlations were found for the total sample.

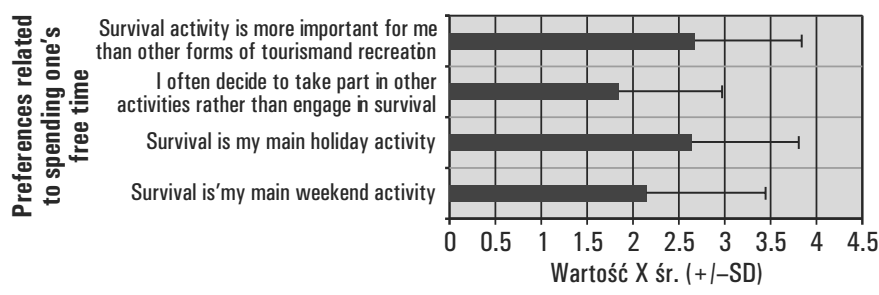

Disagree strongly - 0, Disagree - 1 , Difficult to say -2 , Agree -3 , Agree strongly -4

Figure 4. Preferences related to spending one's free time $(\mathrm{n}=594)$

The study also investigated the level of survival activity, understood as the degree of active participation in survival during the preceding year. This variable is multidimensional and encompasses three indicators.

The first indicator was the frequency of engagement in sur vival activity (fig. 5). The respondents most often declared that they undertook survival either sporadically, i.e. once per 4-6 months, or sometimes, i.e. once per 2-3 months. Only $6 \%$ of the respondents participated in survival activity 1-2 times per week.

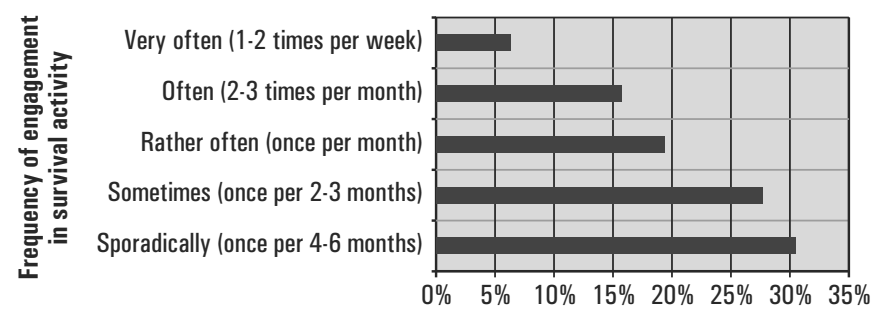

Figure 5. Frequency of engagement in survival activity $(\mathrm{n}=594)$

An analysis of the relationships between the frequency of engagement in survival activity and selected sociodemographic variables and between the frequency of engagement in survival activity and experience showed a significant correlation between the latter two variables for the total sample $(\mathrm{df}=592$; $\mathrm{r}=-0.206, \mathrm{p}<0.05)$.

The second indicator describing the level of survival activity was the duration of individual periods of engaging in this activity (fig. 6). Half of the respondents practised survival as a weekend activity, lasting on average 2-3 days. Much fewer persons (only 1/3 of the total sample) declared undertaking one-day-long survival activity. Respondents who engaged in survival for longer than a week were the least numerous.

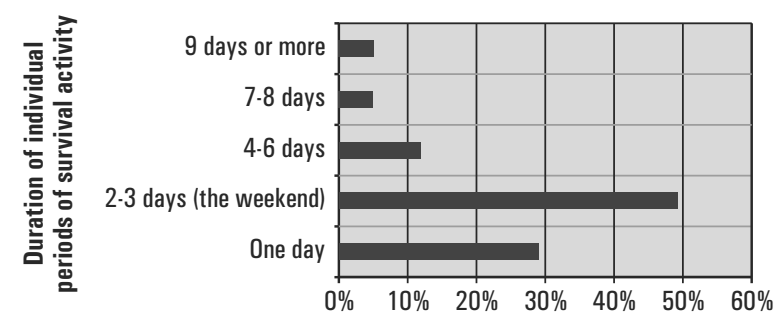

Figure 6. Duration of individual periods of engaging in survival activity $(\mathrm{n}=594)$

Also analysed were the relationships between the duration of individual periods of undertaking survival activity and se-lected sociodemographic variables and between the length of these 
periods and experience. A significant correlation was found in the total sample between the length of individual periods of engaging in survival activity and experience $(\mathrm{df}=592 ; \mathrm{r}=0.249$; $\mathrm{p}<0.05)$.

The last indicator analysed was the number of days spent participating in each form of survival activity within the preceding year. Only the most important results are discussed here due to limitations of space.

The first form of survival activity was one-day trips without an overnight stay (fig. 7). As many as $1 / 3$ of the respondents did not spend even a single day engaging in this form of activity in the preceding year. Among the rest of the respondents, persons who spent 1-5 days on one-day trips constituted the most numerous group. Nearly $6.2 \%$ of the respondents declared spending more than 30 days on one-day trips.

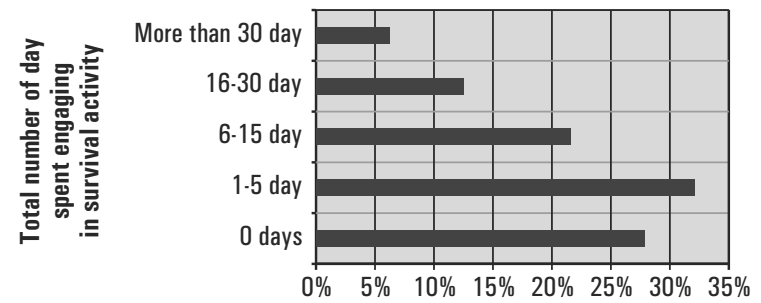

Figure 7. Total number of days spent engaging in survival activity in the preceding year according to forms of organisation: one-day trip $(n=594)$

The second form of survival activity was several-day (no more than three-day-long) trips with overnight stays (fig. 8).

Slightly more than half of the respondents participated in this form of activity in the preceding year. Persons who spent 2-15 days on several-day trips constituted the most numerous group among the respondents, while those who spent more than 30 days on this form of survival activity were the least numerous.

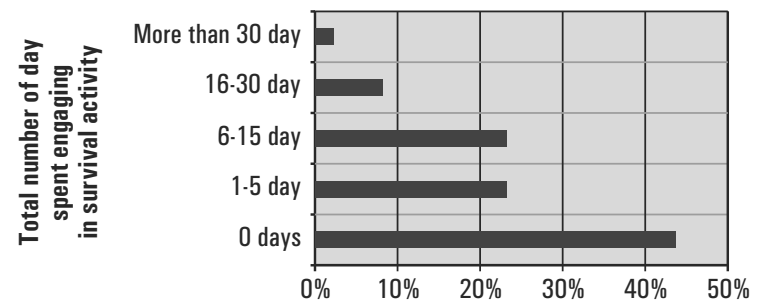

Figure 8. Total number of days spent engaging in survival activity in the preceding year according to forms of organisation: several-day trip $(n=594)$

The remaining forms of survival activity were considerably less popular. As far as rallies and cross-country races are concerned, i.e. activities involving competition, more than half of the respondents (59.1\%) did not spend even a single day engaging in them. The greatest number of respondents participated in rallies and cross-country races for 1-5 days (29.5\%). Only one in 30 respondents spent more than 16 days on rallies. Another form of activity mentioned in the questionnaire was workshops and courses, i.e. educational classes. Only 1/3 of the respondents took part in workshops or courses in the preceding year. The most numerous group were persons who spent 1-5 days on workshops or courses (19.0\%), while those who spent more than 30 days on this form of activity were the least numerous $(0.7 \%)$.

The last form of survival activity analysed were camps, further divided into stationary camps and roaming camps. More than half of the respondents did not take part in any stationary camp in the preceding year. The most numerous group among the remaining respondents spent at least five days engaging in this form of activity (21.2\%). The least numerous group spent more than 30 days at stationary camps $(2.0 \%)$ in the preceding year. Only $1 / 4$ of the respondents took part in roaming camps in the preceding year. The most numerous group spent at least five days undertaking this form of activity (18.0\%), while the least numerous group spent more than 30 days engaging in it during the preceding year $(0.7 \%)$.

\section{Discussion}

Studies on survival as a tourist and recreational activity are rare, both in the Polish and foreign literature. To date, studies have focused on selected groups of respondents $[11,15,16]$ or on particular administrative areas [12]. No comprehensive research has been done on the subject. Nonetheless, the available research constitutes a valuable contribution to the discussion of the results obtained in this study.

The preferred locations for organising survival activity were forests located close to lakes and rivers. Wild and untouched nature constituted an additional advantage. The results of this study confirm the findings obtained by Zarzycki and Opoka [12] and Mogiła-Lisowska et al. [9]. The accessibility of catering and accommodation services was the least important for the respondents. This was probably due the factors described in the model of high-risk recreational activity, according to which the longer a person is engaged in a given form of activity, the more they have a tendency to choose wild and secluded areas [17].

Survival activities were most often organised individually or with a group of friends. Only a small number of respondents organised them with their families or through professional organisers. The participants' experience had an effect on the manner of organising survival activities. The study showed that using services offered by survival associations and organisations was more popular the longer the duration of survival activities was. These results partially contradict the model of highrisk recreational activity in which the social group one participates with in an activity changes with age [17]. If a survival club or association are treated as a small, specialised group (as are friends), then the obtained results contradict the results of previous studies, which indicated that group activities are the most popular [10, 12].

The preferred types of survival activities engaged in by the respondents comprised building makeshift shelters, lighting and building campfires, and topography. In the studies by Tomczak et al. [15] and Korpak [16], paintball, night games, and rope crossing were taken into account. However, the author of this study wishes to emphasise that the literature on the subject involves attempts at considering such activities as climbing, quad and off-road car driving, or paintball [15] as related to survival, and the distinction between the types of activities and forms of organising it tends to be unclear [18]. The least attractive types of activities in this study were city survival, signalling, communication, encryption, and battlefield tactics and simulated military operations. The results show that self-defence, lighting and building campfires, building makeshift shelters, and camouflage and covert movement were less popular the older the respondents were. Moreover, the higher the respondents' level of education was, the smaller their interest in acquiring and cooking meat was.

Most of the respondents indicated that survival was the most important form of tourism and recreation for them and their primary activity during holidays. However, the small number of other studies makes it impossible to compare the obtained results and draw descriptive conclusions.

As far as the frequency of engagement in survival activity is concerned, the respondents declared they participated in it 
sporadically (once per 4-6 months) or sometimes (once per 23 months). The frequency of engagement in survival activity correlated strongly with experience. These results are consistent with the models presented by Nowacki [19] and Winiarski [20], where experience and competences had a significant effect on engagement and activity. In a study by Zarzycki and Opoka [12], the respondents declared they used their survival skills once per week (21\%), during the weekend (19\%), or once per month (23\%). However, in the opinion of the author of this study, this only reflects how often a person made use of their selected skills, rather than indicating their participation in survival activity. An individual period of engaging in survival activity usually lasted 2-3 days (and took place over the weekend) and correlated strongly with experience, as was the case for the frequency of engagement. These results are also consistent with Nowacki's model [19] in which experience and competences have a significant effect on survival activity. Furthermore, the results confirm the data collected by Zarzycki and Opoka [12]: the declared duration of an individual period of survival activity was 2-3 days, with weekend events constituting $43 \%$ and several-day events accounting for $37 \%$. The most popular form of survival activity was one-day trips and several-day trips with overnight stays. These results differ from those obtained in the studies conducted by Zarzycki and Opoka [12] where survival camps and specialist courses were the most popular forms of activity. However, as mentioned above, the respondents' low age and experience may have affected the results. Other forms of activity were definitely less popular, with more than half of the respondents not having taken part in rallies and cross-country races in the preceding year. A similar observation pertains to courses and camps: the share of persons who did not participate in them is even higher, ranging up to $70 \%$. Furthermore, persons who did take part in this form of activity spent no more than 5 days performing it in the preceding year.

\section{Conclusions}

1. Survival activity was strongly determined by the accessibility of the natural environment, including the presence of secluded forests with a diverse terrain and the proximity of lakes and rivers. The respondents who participated in these activities focused on natural assets and considered anthropogenic assets as less important. It can be concluded that the venue of survival activity was strongly determined by whether or not it allowed the respondents to gain new experiences.

2. The results concerning the manner of organising survival activities indicated that the respondents were highly independent. It can be assumed that the low popularity of external organisers, especially during the initial stages of engaging in survival activity, stemmed from the importance of informal groups of friends, who functioned as initiators. Activities offered by survival clubs and associations increased in importance with experience. It can be assumed that this is due to the fact that the respondents searched for specialised activities that they were unable to organise on their own and were willing to share experiences.

3. Activities constituting the foundations of survival were the most popular. This is understandable, as the idea of survival involves acquiring practical skills that make it possible to live in the wilderness and come in direct contact with nature. The low attractiveness of activities related to the military and the urban environment may have stemmed from the fact that such activities are highly specialised (related to the operation of the army, police, and fire-fighters) rather than being part of tourist and recreational activity.

4. Even though survival activity was the main leisure activity engaged in by the respondents, including during the holidays, it was short-term and occasional, the most popular form being weekend trips, sometimes with an overnight stay. This most likely stemmed from the respondents' weekly schedule. The frequency of engagement in survival activity and the duration of individual periods of engaging in it were strongly determined by experience. This may indicate that gaining new experience and thus further developing one's survival skills encouraged the respondents to engage in this activity more frequently.

\section{Literature}

1. Meissner H.O. (1990). Art of Living and Survival. Warszawa: Bellona. [in Polish]

2. Dworzyński M. (1998). Art of survival. Super Tramp 7/8(9), 16. [in Polish]

3. Płoskonka P. (2014). Social Determinants of Participation in Survival as a Form of Tourist and Recreational Activity. Doctoral thesis, Akademia Wychowania Fizycznego Józefa Piłsudskiego w Warszawie. [in Polish]

4. Pękała T. (1998). Basics of survival. Wiedza Obronna 1, 77-86. [in Polish]

5. Kwiatkowski K.J. (2009). Wide horizons of survival. In M. Dycht, L. Marszałek (eds), Dilemmas of (Dis)ability. Musings on the Margin of Cultural and Social Studies (pp. 49-63), Warszawa: Wydawnictwo Salezjańskie. [in Polish]

6. Kwiatkowski K.J. (2012). Survival adventure. In E. PalamerKabacińska, A. Leśny (eds), Education Through Adventure. Outdoor and Adventure Education in Poland. Theory, Examples, and Contexts (pp. 94-109). Warszawa: Pracownia Nauki i Przygody. [in Polish]

7. Tomczak A. (2003). Elements of survival in the educational system for officer cadets in the ground forces. In M. Marcinkowski, M. Sokołowski (eds), Physical Activity, Education, and Health in Defense (Con)texts (pp. 212-223). Poznań: Akademia Wychowania Fizycznego im. Eugeniusza Piaseckiego. [in Polish]

8. Płoskonka P. (2013). Participation in survival as a form tourist and recreational activity in light of research. Studia i Materiały Centrum Edukacji Przyrodniczo-Leśnej 37(4), 248-255. [in Polish]

9. Mogiła-Lisowska J., Dąbrowska-Zielińska K., Śmieszek J. (2012). Survival as a potential tourist product. In W. Siwiński, D.R. Tauber, E. Mucha-Szajek (eds), Theory and Practice of Tourism, Recreation, Accommodation, and Catering Services (pp. 251-258). Poznań: Wyższa Szkoła Hotelarstwa i Gastronomii. [in Polish]

10. Różański P. (2007). Attractiveness of survival classes conducted on wetlands in the opinion of students of the University of Physical Education. Wychowanie Fizyczne i Zdrowotne 5, 13-16. [in Polish]

11. Różański P., Sroka M., Dorosz M. (2005). Knowledge of survival in students of Pope John II State School of Higher Education in Biała Podlaska. In Z. Kubińska, B. Bergier (eds), Physical Recreation in Theory and Practice (pp. 188-191). Biała Podlaska: Państwowa Szkoła Wyższa im. Papieża Jana Pawła II. [in Polish]

12. Zarzycki P., Opoka D. (2007). Survival as a form of adventure tourism taken up by youth in lower Silesia. In D. Umiastowska (ed.), Physical activity of Persons of Different Ages (pp. 110-116). Szczecin: Albatros. [in Polish]

13. Driver B., Brown P., Stankey G.H., Gregoire T.G. (1987). The ROS planning system. evolution, basic concepts and research needed. Leisure Sciences 9(3), 201-212. DOI:10.1080/ 
01490408709512160.

14. Rogalewski O. (1974). Touristic Infrastructure. Warszawa: Wydawnictwa Szkolne i Pedgogiczne. [in Polish]

15. Tomczak A., Różański P., Kuprianiuk A.M. (2012). Opinions of students of the University of Physical Education on survival activities during a summer camp. In M. Sokołowski, A. Kaiser, J. Brzozowski (eds), Holistic Approach Towards Health in Tourism and Recreation (pp. 297-323). Poznań: Wyższa Szkoła Bankowa. [in Polish]

16. Korpak F. (2009). Survival as a free-time activity. In J. Bergier, M. Sroka (eds), Survival in Theory and Practice (pp. 89-92). Biała Podlaska: Państwowa Szkoła Wyższa im. Papieża Jana Pawła II. [in Polish]

17. Ewert A., Hollenhorst S. (1989). Testing the adventure model. Empirical support for a model of risk recreation participation. Journal of Leisure Research 21(2), 124-139.
18. Górka J. (2012). Survival as a form of recreation. In W. Siwiński, B. Pluta (eds), Theory and Methodology of Physical Recreation in Light of Current Research (pp. 92-100). Poznań: Akademia Wychowania Fizycznego im. Eugeniusz Piaseckiego. [in Polish]

19. Nowacki M. (2002). Determinants of Navigational Activity. Poznań: Akademia Wychowania Fizycznego im. Eugeniusz Piaseckiego. [in Polish]

20. Winiarski R.W. (1995). Sports Activity of Youth. Origin, Structure, and Determinants. Kraków: Akademia Wychowania Fizycznego im. Bronisława Czecha. [in Polish]

Submitted: December 9, 2014

Accepted: April 15, 2015 